\title{
Prince Albert youth drug and alcohol use: a comparison study of Prince Albert, Saskatchewan, and Canada youth
}

\author{
Jason $G$. Fenno $M A^{*}$
}

\begin{abstract}
Community Mobilization Prince Albert's (CMPA) Hub and Centre of Responsibility (COR) had been dealing with high rates of youth arrest and referrals to treatment facilities stemming from youth substance abuse. To better help the CMPA craft policies to counter the high rates of youth alcohol and drug use, a study was conducted in June of 2012 that utilized a school survey of PA youth. Data were collected from four local Prince Albert high schools and compared with Saskatchewan and Canadian youth. Analyses of the data were conducted using logistic regression and bivariate correlation. The following paper will provide an overview of the study and explain why youth substance abuse was chosen for this study. Later sections will examine how the Prince Albert school survey was formulated for comparison purposes with Saskatchewan and Canadian youth data obtained from the 2010-11 Youth Smoking Survey (YSS). This will be followed by an overview of the study's key findings, along with results of logistic regression and bivariate correlation analysis and the study's limitations. A final section will examine the implications of this study's findings on youth substance abuse policy and programs for the CMPA Hub and COR, along with the city of PA.
\end{abstract}

Key Words Youth substance use, Youth Smoking Survey, school surveys, addictions, Community Mobilization Prince Albert.

Journal of CSWB. 2016 Nov; 1(3):61-65

www.journalcswb.ca

\section{INTRODUCTION}

Youth alcohol and drug use is a severe social issue with impacts that are felt throughout an entire community. Prince Albert (PA), Saskatchewan is one of the many communities around the world that struggles with youth substance abuse. Statistics from the Prince Albert Police Service (PAPS) (Prince Albert Police Service, 2013) revealed that the number of intoxicated youth being admitted to police custody for their own protection from June 26 to August 29, 2012 was 62 , while only two youth were admitted during the same period in Moose Jaw, a Saskatchewan city of approximately the same size as PA. Furthermore, 655 persons under 19 years of age were admitted to treatment from the Prince Albert Parkland Regional Health Authority, which was only slightly fewer than the number of teenagers admitted in the Regina Qu'Appelle or Saskatoon Regional Health Authority regions (with 786 and 818 admissions, respectively), and those two districts serve much larger populations (Saskatchewan Ministry of Health, 2013). This translates into a rate of treatment of 55.4 per 1,000 Prince Albert youth, 23.6 for 1,000 Regina youth, and 20.6 for 1,000 Saskatoon youth. The state of youth alcohol and drug use in PA has taxed social service agencies and was the reason why a study was urgently needed. A study was agreed upon, utilizing a school survey element and conducted in cooperation between the Community Mobilization Prince Albert's Hub and Centre of Responsibility (COR) staff and the author. The CMPA's Hub and COR were established in 2011 and are modeled to some degree off similar initiatives introduced under Glasgow, Scotland's Violence Reduction Unit (VRU). The first component of the CMPA is the Hub, which focuses on helping at-risk individuals or families in PA within a 24- to 48-hour period via collaborative action plans. The second component is the COR, which focuses on developing long-term solutions to social issues affecting PA, such as substance abuse, violence, and homelessness (Nilson, 2014). As a student researcher originating from Fairbanks, Alaska, a northern community that has also struggled for decades with issues stemming from alcohol and drug abuse in the youth population, building a master's thesis around a study of PA youth substance abuse was of keen interest to the author. 


\section{METHODOLOGY}

\section{Overview of Study}

Three research questions propelled the PA youth alcohol and drug use study:

1. Do a higher percentage of Prince Albert high school students use alcohol or drugs than students in the province of Saskatchewan or the entire nation?

2. Is the severity, onset, or range of alcohol or drug use different for high school students in Prince Albert compared with students in the province of Saskatchewan or the entire nation?

3. What are the demographic, self-esteem, spending and school-related predictors of four indicators of alcohol and drug use in Prince Albert youth?

The Prince Albert Youth Survey (the name given to the survey element of this study) was given to four Prince Albert public high schools between June 13 and 15, 2012. Surveys were administered to grade 9-12 students from four Saskatchewan Rivers School Division high schools: Carlton Comprehensive High School, Prince Albert Collegiate Institute, Wesmor Community High School, and the Won Ska Cultural School. The survey instrument consisted of 15 questions previously used in the Youth Smoking Survey (YSS). The 15 question that made up the Prince Albert Youth Study began with questions that focused on demographic information (Aboriginal or non-Aboriginal, sex, grade level, and weekly spending amount), feelings of school connectedness, and self-esteem. The rest of the survey focused on alcohol and drug use, questions that examined the frequency of use (once a month or less, two to three times a month, and once a week or more), age of first use (12 years or younger to 18 years or older) of alcohol, marijuana, and binge drinking, and the final section examined the use (at least once in a youth's life) of five illicit substances: MDMA (ecstasy, E, X), hallucinogens (LSD, PCP, acid, magic mushrooms, mescaline), cocaine, salvia, and jimson weed.

Similar to the YSS, surveys were constructed using a Scantron or "bubble" answer format that was able to be scored using an optical-machine reader (OMR).

Consistent with the YSS methodology, all of the respondents were anonymous and neither the teachers nor the researchers were able to identify any student who participated. Teachers or school staff administered the surveys to entire classes. School staff members used the same written directions for each class participating in the survey and were instructed on how to administer the survey, including time limits to complete the questionnaire, what to do if students did not want to complete the survey, and instructions in case a student became distressed or emotionally upset while taking the survey. Students were told by the teachers administering the survey that their participation was completely voluntary, that no one but the researchers would see their responses, and that researchers did not have access to any information that would identify the students. Honestly answering the questions was stressed in the instructions and students were advised that they could stop taking the survey at any time, or refuse to answer any question(s) without penalty. All students were told that, if at any time during the survey they felt uncomfortable, they could stop and place their survey into an envelope provided to the survey administrators. With the completion of the survey, youths were implying that they were consenting to participate in the project. In addition, students were sampled according to their classroom assignment (e.g., only students in classes assigned to take the survey were able to participate). An active information-passive permission approach was utilized to notify parents of the survey. Using this approach, letters were mailed to parents describing the survey and gave parents three options (call, letter or e-mail) to notify schools or the researcher that their child(ren) was not to participate in the survey. As a result, if no contact from a parent was received, it was assumed that the youth was permitted to participate. It is important to note that the University of Regina research ethics board fully approved of this study, including the PA Youth Survey.

All of the Prince Albert Youth Survey items were drawn from the YSS survey for two reasons. First, the survey items used in the YSS had a long history of use in Canadian schools. Second, by using the same questions, the Prince Albert results could be compared with the results from the rest of the nation. Most of the survey items were constructed using a Likert-type format, where respondents were asked to choose the option on the survey that was closest to what they thought or felt was the true answer for them (e.g., whether they strongly disagreed, disagreed, agreed or strongly agreed with a statement). A total of 1,394 surveys were distributed to the four participating PA high schools, and altogether there were 921 usable surveys, as not all students participated and some surveys could not be scored.

\section{0-11 Youth Smoking Survey (YSS)}

Comparison data utilized for this study came from the 201011 Youth Smoking Survey (YSS). The YSS has been administered by the Propel Centre for Population Health Impact (2011) located on the campus of the University of Waterloo every other year since 1994 across Canada. The total comparison data that were used for this study from Canada was from the 2010-11 YSS for grades 9-12 was 31,396 (New Brunswick did not participate in the 2010-11 YSS). Saskatchewan's comparison data from the 2010-11 YSS for grades 9-12 was 1,608. All of the 15 questions that made up the PA Youth Survey were duplicated from the 2010-11 YSS. This was done for validity purposes, since the YSS is a stringent national study of Canadian youth and suitable for comparison purposes with PA youth to answer the three research questions that guided this study. The next section will examine the key findings from the Prince Albert Youth Study.

\section{RESULTS \& DISCUSSION}

\section{Key Findings}

The results of the demographic questions were fairly similar between the Prince Albert, Saskatchewan, and Canadian youth, although there were two areas of note for this section of the survey. The first was that 307 Prince Albert youth (33.3\%) indicated that they were Aboriginal persons. By contrast, $13.3 \%$ of the Saskatchewan sample and $6.4 \%$ of the national sample indicated that they were Aboriginal. The second was that Prince Albert youth indicated that they had 
less spending money per week when compared to the two comparison populations.

The next two sections of the survey focused on selfesteem and school connectedness. A larger proportion of Prince Albert youth reported that they agreed with the statement that they "liked the way I am" (52.8\%) than the Saskatchewan $(30.2 \%)$ or national samples $(44.6 \%)$. A larger proportion of Prince Albert youth also reported that they "liked the way they looked" (40.4\%) than the Saskatchewan $(35 \%)$ or Canadian $(30.7 \%)$ samples. The third self-esteem item examined was "when I do something I do it well" and Prince Albert youth again had higher levels of agreement with that statement (33.3\%) than the Saskatchewan (30.2\%) or Canadian (26.9\%) samples. The school connectedness survey items displayed a similar pattern as the self-esteem questions, with $81 \%$ of the Prince Albert youth indicating that they strongly agreed or agreed that they "felt close to people at their school," compared to the Saskatchewan (80.2\%) and Canadian youth (79\%). Over four-fifths of the Prince Albert sample $(85.8 \%)$ indicated that they were happy to be at their school, while smaller proportions of the Saskatchewan (76\%) or Canadian (75.4\%) samples expressed the same sentiment.

The results for the next section of the survey focused on alcohol, marijuana, and binge drinking in the past 12 months, and in all three categories (once a month or less, two to three times a month, and once a week or more) a much higher proportion of the Prince Albert youth reported using alcohol. Almost one-third (32.3\%) of the Prince Albert respondents reported drinking at least once a week, which was much higher than the Saskatchewan (19.2\%) or Canadian (13.2\%) samples. 23.1\% of the Prince Albert youth were using marijuana at least once a month compared with $8.5 \%$ of the Saskatchewan and $11.6 \%$ of the Canadian respondents. It is noteworthy that over twice as many Prince Albert youth reported using marijuana at least once per week (27.3\%) than the youth from the Saskatchewan $(9.1 \%)$ or Canadian $(11.9 \%)$ samples. Prince Albert youth also had higher rates of selfreported binge drinking and that $17 \%$ of the Prince Albert youth binge drank once a week or more, which was higher than the Saskatchewan or national samples. The Table I below illustrates all the PA youth alcohol, marijuana, and binge drinking use results in comparison with Saskatchewan and Canadian youth.

The age of first alcohol use (more than a sip), binge drinking, and marijuana use in the three samples was the next section of the survey. Overall the results show that a higher percentage of Prince Albert youth used marijuana, drank alcohol (more than a sip), and binge drank at a younger age than the provincial and national samples. With respect to marijuana use, a higher percentage of youth in the Prince Albert sample reported having used marijuana for all seven age categories than their counterparts in the Saskatchewan and Canadian samples. Over one-tenth $(11.5 \%)$ of Prince Albert youth indicated that they started using marijuana at 12 years or younger, which was almost double the proportions reported by respondents in the Saskatchewan (6.2\%) and Canadian (6.1\%) samples. In terms of first alcohol use (more than a sip), a larger proportion of the Prince Albert respondents used alcohol at a younger age than either the Saskatchewan or Canada samples, which was observed for all seven of the age categories. It is noteworthy that $30.4 \%$ of
TABLE I Percentage of youth reporting alcohol, marijuana, and binge drinking, Prince Albert, Saskatchewan, and Canadian samples

\begin{tabular}{lccc}
\hline \multicolumn{1}{c}{ Substance } & $\begin{array}{c}\text { Prince } \\
\text { Albert } \\
(\%)\end{array}$ & $\begin{array}{c}\text { Saskatchewan } \\
(\%)\end{array}$ & $\begin{array}{c}\text { Canada } \\
(\%)\end{array}$ \\
\hline $\begin{array}{l}\text { Alcohol Use: } \\
\text { Once a month or less }\end{array}$ & 33.8 & 25.1 & 25 \\
2 to 3 times a month & 31.3 & 18.3 & 15.1 \\
Once a week or more & 32.3 & 19.2 & 13.2 \\
Marijuana Use: & & & \\
Once a month or less & 23.1 & 8.5 & 11.6 \\
2 to 3 times a month & 5.8 & 2.9 & 3.9 \\
Once a week or more & 27.1 & 9.1 & 11.9 \\
Binge Drinking: & & & \\
Once a month or less & 29.8 & 25.3 & 22.8 \\
2 to 3 times a month & 14.7 & 14.2 & 10.6 \\
Once a week or more & 17.0 & 11.5 & 8.2 \\
\hline
\end{tabular}

Prince Albert youth indicated that they had started using alcohol at 12 years or younger, which was much higher than the Saskatchewan $(19.8 \%)$ and national $(15.5 \%)$ samples. The final category examined was binge drinking and the results showed a similar pattern to the respondent's first marijuana and alcohol use. Up to the age of 12 years the self-reported binge drinking of the Prince Albert and Saskatchewan samples were similar, although the Canadian sample was slightly lower. For all other age categories, however, the Prince Albert respondents had higher levels of self-reported binge drinking. The Table II below illustrates all of PA results of the age of first use of alcohol (more than a sip), marijuana, and binge drinking use compared with Saskatchewan and Canadian youth.

The last area of survey asked PA youth whether they had used or tried an illicit substance (MDMA, hallucinogens, cocaine, salvia and jimson weed). Results found that the highest rate of use for any of the illicit substances for Prince Albert youth was MDMA (13.5\%), which was much higher than the Saskatchewan $(4.6 \%)$ or Canadian $(6.6 \%)$ samples. The four other illicit drugs that Prince Albert youth reported using were hallucinogens, salvia, cocaine, and jimson weed, and usage for all of these substances was higher than the other two samples. The total frequency of use of the five illicit drugs being used or tried at least once by each sample was 22.1\% for Prince Albert respondents; Saskatchewan sample was $7.4 \%$, and the Canadian sample was $9.4 \%$. The Table III below illustrates all of the PA results from the five illicit substances that had the highest frequency of use compared with Saskatchewan and Canadian youth.

\section{Logistic Regression Analysis Results}

Out of the six predictor variables (age, gender, Aboriginal, self-esteem, school connectedness, and weekly spending) examined in the logistic regression model analysis for predicating alcohol and binge drinking use in the past 12 months, only age and school connectedness were statistically 
TABLE II Percentage of first alcohol (more than a sip), marijuana, and binge drinking use by age

\begin{tabular}{|c|c|c|c|}
\hline Substance & $\begin{array}{c}\text { Prince } \\
\text { Albert } \\
(\%)\end{array}$ & $\begin{array}{c}\text { Saskatchewan } \\
(\%)\end{array}$ & $\begin{array}{c}\text { Canada } \\
(\%)\end{array}$ \\
\hline \multicolumn{4}{|l|}{ Marijuana Use: } \\
\hline 12 years or younger & 11.5 & 6.2 & 6.1 \\
\hline 13 years & 7.7 & 3.3 & 5.3 \\
\hline 14 years & 9.4 & 4.7 & 8.5 \\
\hline 15 years & 10.1 & 5.4 & 7.2 \\
\hline 16 years & 5.3 & 3.6 & 4.3 \\
\hline 17 years & 1.6 & 1.4 & 1.1 \\
\hline 18 years & .3 & .1 & .1 \\
\hline \multicolumn{4}{|c|}{ Alcohol Use (More than a sip): } \\
\hline 12 years of younger & 30.4 & 19.8 & 15.5 \\
\hline 13 years & 18.4 & 11.7 & 11.4 \\
\hline 14 years & 27.7 & 15.9 & 13.9 \\
\hline 15 years & 14.6 & 11.8 & 9.4 \\
\hline 16 years & 5.8 & 2.9 & 3.8 \\
\hline 17 years & .7 & .9 & .9 \\
\hline 18 years or older & .7 & .2 & .2 \\
\hline \multicolumn{4}{|l|}{ Binge Drinking: } \\
\hline 12 years of younger & 7.2 & 7.3 & 5.4 \\
\hline 13 years & 10.3 & 7.8 & 6.5 \\
\hline 14 years & 17.9 & 13.6 & 11.9 \\
\hline 15 years & 18.6 & 14.8 & 11.3 \\
\hline 16 years & 9.0 & 6.0 & 6.0 \\
\hline 17 years & 2.0 & 1.6 & 1.6 \\
\hline 18 years or older & .9 & .3 & .3 \\
\hline
\end{tabular}

significant. The odds of a youth drinking alcohol in the previous 12 months were 1.362 times higher when the youth was older and 1.093 times higher if that youth was less connected with their school. Furthermore, the odds of a youth binge drinking in the previous 12 months were 1.454 times higher for older youth and 1.092 times higher for youth who were less connected with their schools.

For marijuana use in the past 12 months and lifetime illicit drug use (MDMA, hallucinogens, cocaine, salvia, and jimson weed) two variables were statically significant: age and being Aboriginal. The odds of a youth using one of the top five illicit drugs were 35\% higher for older youth and 59.8\% for Aboriginal youth. Furthermore, the odds of a youth using marijuana were 1.203 times higher for older youth and $68.5 \%$ higher for Aboriginal youth.

\section{Bivariate Correlation Analysis Results}

The bivariate correlation analysis examined the relationship between the four dependent variables: drinking/nondrinking; binge drinking/non-binge drinking; marijuana use/non user; and whether the respondent used one of the top five illicit drugs: MDMA, hallucinogens, cocaine, salvia, and jimson weed; and the six independent variables (age, gender, Aboriginal, self-esteem, school connectedness, and weekly spending) used in this study. Drinking alcohol was positively associated with binge drinking and illicit drug use (the only significant association among the four dependent variables). Also, drinking and binge drinking were positively or significantly associated with age, weekly spending money, and lower school connectedness. Marijuana use was positively associated with age, being Aboriginal, and having lower self-esteem, and illicit drug use was positively associated with age and being Aboriginal.

\section{Limitations}

This study suffered from a limited number of communityrelated predictor variables, which would have helped better understand the complexities surrounding youth alcohol and drug use. The Prince Albert data were from 2012, while the Saskatchewan and Canadian samples were from the 2010-11 school year, and the two Prince Albert Catholic high schools (St. Mary's and River Academy) did not participate in this study. Lastly, comparisons between the four schools were not able to be drawn because of limitations in the data that were collected.

\section{CONCLUSIONS \& POLICY IMPLICATIONS FOR THE CMPA}

The main takeaways from this study are that PA high school students indicated that their age of onset for alcohol, marijuana, and binge drinking use were at earlier ages than either of the two comparison populations from the rest of the province or the nation. In addition, when PA high school students did use alcohol or marijuana, they indicated using both at higher rates than either of the two comparison populations. PA high school students also indicated using illicit drugs at higher rates than the two comparison populations.

The logistic regression models found that age was the only characteristic that consistently predicted alcohol, binge drinking, marijuana, and illicit drug use. Less school connectedness predicted the use of alcohol and binge drinking. Alcohol use predicted both binge drinking and illicit drug use. Marijuana and illicit drug use was also predicated by youth who indicated they were Aboriginal.

There are a number of potential policy implications that the results of this study bring to light for the CMPA Hub and COR initiative. One would be expanding and generating added funding for the current youth outreach via Hub meetings that put together collaborative at-risk youth action plans to reach out to at-risk youth in PA. In addition, COR program expansion could be in areas of social services that the Hub intervention teams rely upon for support when putting together action plans, such as the Margo Frournier Centre, Valley Hill, Youth Addictions Services, PA Métis Addictions Council, and the Victoria Hospital youth detoxification program.

Strengthening school-based intervention programs (Won Ska Cultural School), as well as non-school-based intervention/education alcohol and drug strategies should also be examined. Expanding current community-based youth programs (youth counselors, sports leagues, eleven Community Clubs, and Big Brothers Big Sisters) that provide 
TABLE III The five illicit substances that had the highest frequency of being used or tried

\begin{tabular}{|c|c|c|c|}
\hline Substance & $\begin{array}{l}\text { PA youth who have used or } \\
\text { tried at least once in } \\
\text { their life } \\
(\%)\end{array}$ & $\begin{array}{l}\text { SK youth who have used or } \\
\text { tried at least once in } \\
\text { their life } \\
(\%)\end{array}$ & $\begin{array}{c}\text { Canadian youth who have } \\
\text { used or tried at least once } \\
\text { in their life } \\
(\%)\end{array}$ \\
\hline MDMA (ecstasy, E, X) & 13.5 & 4.6 & 6.6 \\
\hline $\begin{array}{l}\text { Hallucinogens (LSD, PCP, acid, magic } \\
\text { mushrooms, mescaline) }\end{array}$ & 12.9 & 4.9 & 6.9 \\
\hline Cocaine & 9.1 & 3.8 & 3.4 \\
\hline Salvia & 9.0 & 3.6 & 5.1 \\
\hline Jimson Weed & 4.5 & 2.2 & 2.0 \\
\hline $\begin{array}{l}\text { Total frequency of the top five illicit drugs } \\
\text { used at least once }\end{array}$ & 22.1 & 7.4 & 9.4 \\
\hline
\end{tabular}

PA youth positive activities to participate in, and which also help to boost self-esteem, should also be considered. This is an area of program expansion that is of an utmost importance because PA youth indicated having higher levels of self-esteem than either of the two comparison populations on the PA Youth Survey. Any new or expanded programs should focus in on building up PA youth self-esteem and channeling it into alternative actives, along with setting positive life goals. School-based interventions should be expanded, along with training and employing additional youth outreach workers.

In addition, Aboriginal youth programs must be part of any solution to counter high rates of illicit drug and marijuana use as indicated by the PA Youth Survey. Prince Albert has a high proportion of Aboriginal persons in the population and this group may have higher unmet needs than other populations, given their histories of loss and discrimination. Connecting PA Aboriginal youth with positive Aboriginal mentors (the Young Women's Christian Association, the Aboriginal Mentoring Program offered through PAPS, and Bold Eagle) and their own traditions, along with elders, could help instill pride and resiliency that could help counter marijuana and illicit drug use (Dell, Dell, \& Hopkins, 2005; Jiwa, Kelly, \& St. Pierre-Hanson, 2008; McCormick, 2000; Tousignant \& Sioui, 2009).

Lastly, the results of this project greatly helped the PA CMPA COR shape their strategies for responding to youth alcohol and drug use, along with the issues that stem from youth substance abuse. The results of the PA Youth Survey assisted the COR with identifying the substances and the ages that PA youth start to use alcohol and marijuana, and binge drink. The results also illustrated that illicit substance abuse is a serious problem for PA youth. All of these results amplify the ability of the CMPA COR to forecast long-term solutions for the most pressing needs of PA youth who are struggling with substance abuse. Moreover, self-esteem and school connectedness results informed the CMPA COR where resources could be shifted to expand on current programs or establish new ones. The positive view that PA youth had of their schools and how they felt at school is an additional area where interventions could take place to reach out to troubled PA youth. Results of the PA Youth Survey also aided in the formation of the city of Prince Albert's community-wide alcohol strategy.

\section{ACKNOWLEDGMENTS}

I would like to thank all of the peer reviewers and especially Editor in Chief Norm Taylor for initially reaching out to me about publishing my thesis.

\section{CONFLICT OF INTEREST DISCLOSURES}

This piece has been a shortened version of the authors master's thesis that was written in accordance with the requirements of the University of Regina's MA in Police Studies program. The thesis was titled "An Examination of Youth Alcohol and Drug Use in Prince Albert" and Dr. Rick Ruddell was the author's thesis supervisor.

\section{AUTHOR AFFILIATIONS}

*Police Studies, University of Regina, Regina, SK, Canada.

\section{REFERENCES}

Dell, C., Dell, D., \& Hopkins, C. (2005). Resiliency and holistic inhalant abuse treatment. Journal of Aboriginal Health, 2(1), 4-13.

Jiwa, A., Kelly, L., \& Pierre-Hansen, N. (2008). Healing the community to heal the individual literature review of Aboriginal community-based alcohol and substance abuse programs. Canadian Family Physician, 54(7), 1000.

McCormick, R. (2000). Aboriginal traditions in the treatment of substance abuse. Canadian Journal of Counseling and Psychotherapy, 34(1), 25-32.

Nilson, C. (2014). Risk-driven collaborative intervention: a preliminary impact assessment of community mobilization Prince Albert's Hub model. Saskatoon, SK: University of Saskatchewan. Retrieved from: http://www.usask.ca/cfbsjs/research/pdf/research_reports/ RiskDrivenCollaborativelntervention.pdf

Prince Albert Police Service (2013). Prince Albert Police Service 2012 year-end statistics. Prince Albert, SK: Prince Albert Police Service.

Propel Centre for Population Health Impact. (2011). Youth smoking survey (YSS): 2010/2011. YSS microdata user guide. Waterloo, ON: University of Waterloo.

Saskatchewan Ministry of Health. (2013). Covered Populations 2011. Tables by Regional Health Authority. Summary of all regional health authorities by sex and age group: \#5: Sunrise Regional Health Authority. Regina, SK: Ministry of Health. p. 81

Tousignant, M., \& Sioui, N. (2009). Resilience and Aboriginal communities in crisis: theory and interventions. Journal of Aboriginal Health, 5(1) 43-61. Retrieved from: http://www.naho.ca/documents/journal/ jah05_01/05_01_03_Resilience.pdf 